\title{
Controlling Chromium Vaporization from Interconnects with Nickel Coatings in Solid Oxide Devices
}

\author{
Michael V. Glazoff ${ }^{\left(1,{ }^{*}\right)}$, Sergey N. Rashkeev ${ }^{(2, * *)}$, and J. Stephen Herring ${ }^{(3)}$ \\ (I) Advanced Process and Decision Systems, Idaho National Laboratory, Idaho Falls, ID 83415 \\ ${ }^{(2)}$ Center for Advanced Modeling \& Simulation, Idaho National Laboratory, Idaho Falls, ID 83415 \\ ${ }^{(3)}$ Nuclear Systems Design and Analysis, Idaho National Laboratory, Idaho Falls, ID 83415
}

Vaporization of Cr-rich volatile species from interconnect materials is a major source of degradation that limits the lifetime of planar solid oxide devices (solid oxide fuel cells and solid oxide electrolysis cells) with metallic interconnects. Some metallic coatings ( $\mathrm{Ni}, \mathrm{Co}$, and $\mathrm{Cu}$ ) may significantly reduce the $\mathrm{Cr}$ release from interconnects and slow down the oxide scale growth on the steel substrate. To shed additional light upon the mechanisms of such protection and find a suitable coating material for ferritic stainless steel materials widely used for interconnects, we used a combination of first-principles calculations, thermodynamics, and diffusion modeling to investigate which factors determine the quality of the Ni metallic coatings. We found that $\mathrm{Cr}$ migration in $\mathrm{Ni}$ coatings is determined by a delicate combination of the nickel oxidation, $\mathrm{Cr}$ diffusion, and phase transformation processes. Although the formation of $\mathrm{Cr}_{2} \mathrm{O}_{3}$ is more exothermic than that of $\mathrm{NiO}$, the kinetic rate of the chromia formation in the coating layer and its surface is significantly reduced by the low mobility of $\mathrm{Cr}$ in nickel oxide and in $\mathrm{NiCr}_{2} \mathrm{O}_{4}$ spinel. These results are in a good agreement with diffusion modeling for $\mathrm{Cr}$ diffusion through the $\mathrm{Ni}$ coating layer on the ferritic 441 steel substrate and available experimental data.

\footnotetext{
*All correspondence should be sent to: Michael.Glazoff@inl.gov; Phone: (208) 526 8937; Fax: (208) 5263677

** Present address: Qatar Foundation, Qatar Environment and Energy Research Institute, P. O. Box 5825, Doha, Qatar
} 


\section{Submitted for publication in International Journal of Hydrogen Energy}

\section{Introduction}

Metallic interconnects act as engineering barriers between anode and cathode gases and provide the electronic connection between the single cells in the stack of planar solid oxide fuel cells (SOFC) [1] and solid oxide electrolysis cells (SOEC) [2]. SOFCs devices produce electricity directly from oxidizing a fuel, while SOECs produce oxygen and hydrogen gas in the process of steam electrolysis. These high temperature solid oxide devices place stringent requirements on materials used for the cell construction. In fact, appropriate materials for cell components are very scarce [3]. The most important consideration is the matching of the thermal expansion coefficients of electrode materials with that of the electrolyte to guarantee the high quality of the interfaces and to prevent cracking and/or delamination of the device components either during high temperature operation or heating/cooling cycles. Other technical requirements for these materials include a high resistance against oxidation and creep at temperatures $750-900^{\circ} \mathrm{C}$ in aggressive environment (hydrogen, oxygen, water vapor, etc.) and a high electrical conductivity of the surface oxide scales.

Ferritic steels with chromium contents $>20 \mathrm{wt} . \%$ and $\mathrm{Cr}$ based alloys were identified as the best materials for metallic interconnects because of their ability to form $\mathrm{Cr}_{2} \mathrm{O}_{3}$ scales that protect the material from rapid oxidation while retaining a reasonably high electrical conductivity [4]. However, these materials have tendency to release gaseous $\mathrm{Cr}$ species during solid oxide device operation $[5,6]$. These volatile $\mathrm{Cr}$ species are reduced at different locations of electrodes, electrolyte, and their interfaces and form Cr-rich phases [7] which inhibits the electrochemical processes in the cell. This effect is often called "Cr poisoning"; the corresponding degradation mechanisms of components of solid oxide devices with interconnects fabricated out of different Cr containing materials were proposed and extensively discussed in the previous publications [8$18]$. 


\section{Submitted for publication in International Journal of Hydrogen Energy}

Different metallic and metal oxide coatings may significantly slow down the $\mathrm{Cr}$ retention from stainless steel interconnects [19]. The best $\mathrm{Cr}$ retention capabilities were observed for alumina scales formed at the top of aluminum containing alloys. However, the high electrical resistance of alumina, which is five orders of magnitude higher than that of chromia [20], makes alumina forming alloys seemingly unsuitable as interconnect material. $\mathrm{The}^{\mathrm{TiO}_{2}}$ layers formed on top of Nicrofer-7520 alloy turned out to be less effective as they were partially broken up and overgrown by $\mathrm{Cr}$-Fe-spinel which could be the result of the porosity and the uneven morphology of the underlying $\mathrm{Fe}-\mathrm{Cr}$ oxide.

Metallic coatings of $\mathrm{Co}, \mathrm{Cu}$ and $\mathrm{Ni}$ are considered as promising coating materials for metallic solid oxide devices interconnects. The $\mathrm{Co}, \mathrm{Cu}$ and $\mathrm{Ni}$ coatings showed a reduction of the $\mathrm{Cr}$ release by more than 2 orders of magnitude compared to the uncoated substrate material of Crofer $22 \mathrm{APU}$, or by about 3 orders of magnitude compared to pure chromia scales at $800^{\circ} \mathrm{C}$ in humid air [19]. Even after $900 \mathrm{~h}$ or $1200 \mathrm{~h}$ of operation at $800{ }^{\circ} \mathrm{C}$ in humid air and 3-4 thermal cycles to room temperature no decrease of the Cr retention was observed. The SEM/EDX analyses shows, that the metallic $\mathrm{Co}, \mathrm{Cu}$, and $\mathrm{Ni}$ coatings were completely oxidized during the annealing at 800 ${ }^{\circ} \mathrm{C}$ in humid air, and the coating layers consisted of $\mathrm{Co}_{3} \mathrm{O}_{4}, \mathrm{CuO}$ and $\mathrm{NiO}$, respectively. The literature values of the electrical conductivities for all of these oxides are 1-2 orders of magnitude higher than that of $\mathrm{Cr}_{2} \mathrm{O}_{3}$. Also, the oxidized metallic coatings formed effective barriers against oxidation of the substrate material. Advantages of metallic $\mathrm{Co}$, $\mathrm{Ni}$ or $\mathrm{Cu}$ coatings are their low costs and easy and rapid fabrication by a wide range of techniques.

The aim of this study is to understand which properties of the coating systems are responsible for reducing the $\mathrm{Cr}$ vaporization from stainless steels used as interconnectors and the increase of the electronic conductivity of the interconnector by reducing the growth of sublayered chromia scales. For this purpose, we used a combination of first-principles calculations, thermodynamic, and diffusion modeling for $\mathrm{Cr}$ behavior in oxidized and unoxidized $\mathrm{Ni}$ coating positioned on the top of stainless steel. We found that Cr migration through the coating film is defined by the two 
main competing factors: (i) high $\mathrm{Cr}$ solubility in unoxidized $\mathrm{Ni}$ matrix, and (ii) possible chromium and nickel oxides segregation in oxidized Cr-Ni alloys. Coating oxidation process significantly increases the resistance of the film to $\mathrm{Cr}$ migration and is crucially important for controlling the $\mathrm{Cr}$ species evaporation from $\mathrm{Cr}$ containing interconnects.

\section{Brief Review of Thermodynamics and Kinetics of Oxidation of Metallic Materials}

The minimization of $\mathrm{Cr}$ evaporation from a coated interconnect may be caused by one of the three reasons: (i) Cr diffusion through the coating layer takes a sufficiently long time; (ii) Coating layer gets oxidized itself and forms oxide(s) different from $\mathrm{Cr}_{2} \mathrm{O}_{3}$. The $\mathrm{Cr}$ migration rate through these oxides is different from the $\mathrm{Cr}$ migration rate in unoxidized metallic coating. In turn, this may slow down the formation of chromium oxide islands at the gas-coating interface and, therefore, slow down the release of gaseous Cr-bearing species; (iii) Complex oxides such as spinels may be formed because of solid state reaction between $\mathrm{Cr}_{2} \mathrm{O}_{3}$ and oxides formed in the coating layer which may bind $\mathrm{Cr}$ in a complex oxide layer and thereby prevent its migration to the gas-coating interface.

First, we investigated the oxidation thermodynamics of the coating materials. It was done using the ThermoCalc AB software version S (Stockholm, Sweden) [21], and the TTFE6 database. This software employs the so-called CALPHAD approach (CALculation of PHase Diagrams) allowing for conducting self-consistent evaluation of the thermodynamic properties of a given material, and the corresponding phase diagram [22-24]. We used it to compute the binary Fe-Cr-O and Ni-Cr-O isothermal cross-sections at $1073 \mathrm{~K}\left(800^{\circ} \mathrm{C}\right)$ to assess the mutual solubility of $\mathrm{Cr}$ in $\mathrm{Fe}$ and in $\mathrm{Ni}$ in the presence of oxygen. One of our goals was to assess the values of the dissociation pressure for different oxides of interest. The so-called "dissociation pressure" for 
a given oxide (it is defined as the unique partial equilibrium pressure of oxygen gas at which the metal and its oxide coexist) is calculated for the $A_{m} B_{n}$ oxide as follows [25]:

$$
\Delta G_{A_{m} B_{n}}^{0}=\frac{m}{2} R T \ln \left(p_{O_{2}}^{\text {diss. }}\right)
$$

In expression (1), $R$ stands for the universal gas constant, $T$ is the absolute temperature, and $\Delta G_{A_{m} B_{n}}^{0}$ is the standard Gibbs free energy of the formation of the corresponding oxide, $A_{m} B_{n}$. When deriving this expression, we took into account that the activities of the solid metal and its oxide are equal to unity [25]. In the modified Ellingham - Richardson diagram in Figure 1, the values of the corresponding $\Delta G_{A_{m} B_{n}}^{0}$ were used to calculate the dissociation pressures for different oxides [26]. These values of $\Delta G_{A_{m} B_{n}}^{0}$ are not plotted in the figure. Instead, the dissociation pressure for the several oxides was plotted as a function of temperature [26]. If the oxygen pressure in the system is higher than the dissociation pressure of its oxide, then the metal surface will remain unoxidized. If the opposite case is realized, then the $A_{m} B_{n}$ oxide will be stable.

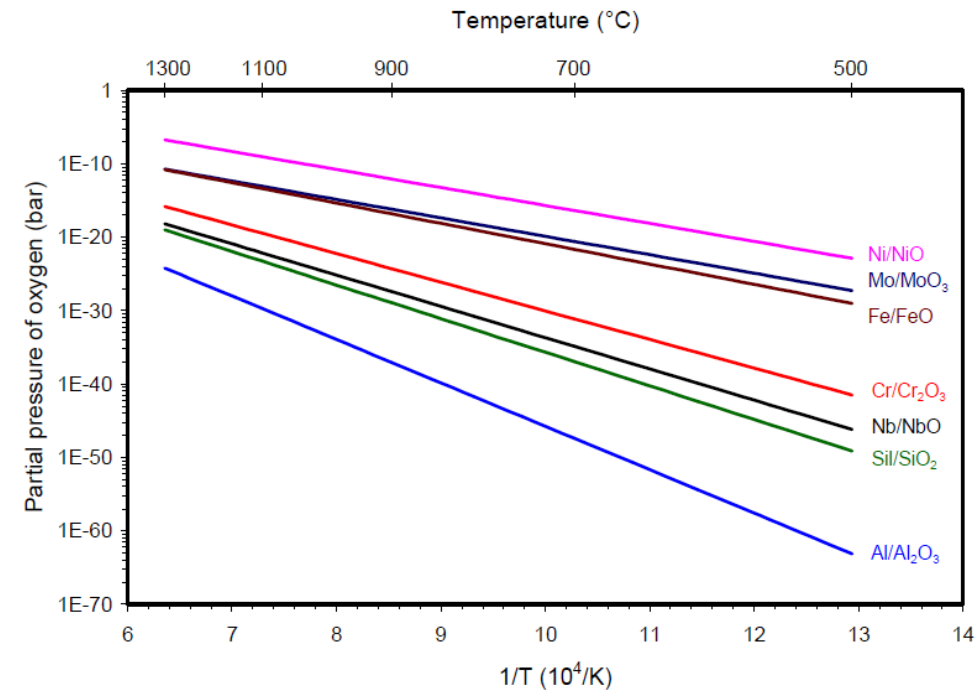

Figure 1 The modified Ellingham-Richardson diagram illustrating oxidation of different metals ( $\mathrm{Ni}, \mathrm{Mo}, \mathrm{Fe}, \mathrm{Cr}, \mathrm{Nb}, \mathrm{Si}$, and $\mathrm{Al}$ ) as a function of temperature [26]. 
From the analysis of Figure 1 it becomes clear that, from a thermodynamic perspective, the formation of the $\mathrm{Cr}_{2} \mathrm{O}_{3}$ oxide is energetically more favorable than that of $\mathrm{NiO}, \mathrm{MoO}_{3}$, and $\mathrm{FeO}$, while it is less favorable than the formation of $\mathrm{SiO}_{2}, \mathrm{Al}_{2} \mathrm{O}_{3}$, and $\mathrm{NbO}$. Thus, in the presence of a significant amount of $\mathrm{Cr}$, formation of $\mathrm{Cr}$ oxide islands on the surface of the 441 ferritic steel alloy, typically used as a material of choice for interconnects, is thermodynamically favored, if one neglects possible kinetic effects in the oxidation process. If, however, one starts with a freshly deposited coating, i.e., at the initial moments the Ni coating layer does not contain any chromium at the coating surface, then the question of reducing the evaporation of chromium will depend, to a significant extent, on the kinetics of the $\mathrm{Cr}$ oxidation and $\mathrm{Cr}$ diffusion through a partially oxidized Ni-coating.

The solubility limit for $\mathrm{Cr}$ in $\mathrm{NiO}$ is quite low even at $\mathrm{T}=1073 \mathrm{~K}$ (corresponding to a typical operating temperature of a solid oxide device), see Figures 2 and 3. Instead, the $\mathrm{NiCr}_{2} \mathrm{O}_{4}$ spinel is formed in which the mobility of $\mathrm{Cr}$ is quite low [20]. Therefore, the rate of the chromia formation in the Ni coating layer will be significantly reduced. This can be seen from the constructed Ni-CrO ternary phase diagram (an isothermal cross-section at $1000^{\circ} \mathrm{C}$ ), see Figure 2 below:

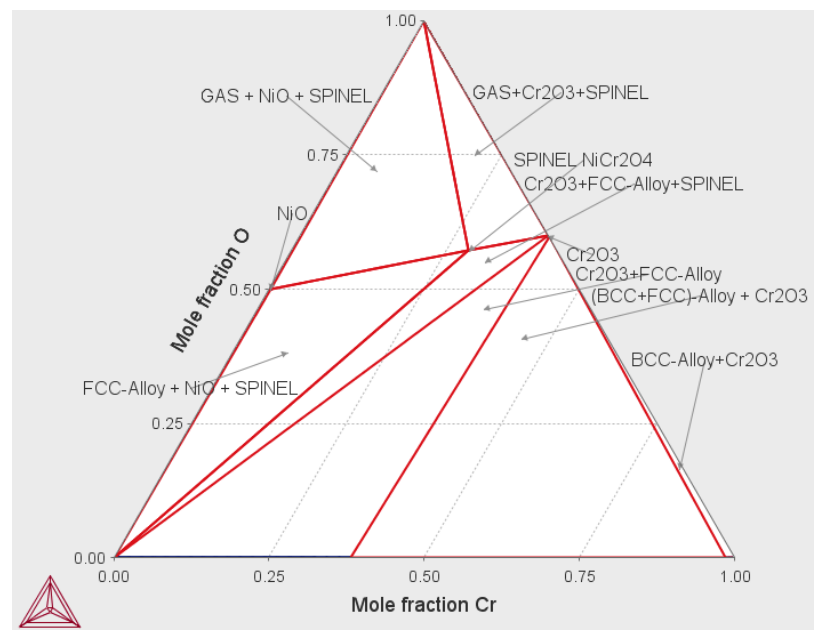

Figure 2 Isothermal cross-section of the Ni-Cr-O phase diagram at $1073 \mathrm{~K}$. Spinel corresponds to the ceramic phase $\mathrm{NiCr}_{2} \mathrm{O}_{4}$. For the metallic phases, we use the general 
designation "alloy" (can be BCC, FCC, or mixed structure) in the calculations. The red lines separate different phase fields in the system. The 3.1 version of the Thermo-Calc softwarereleased on November 2013) was used in all our calculations.

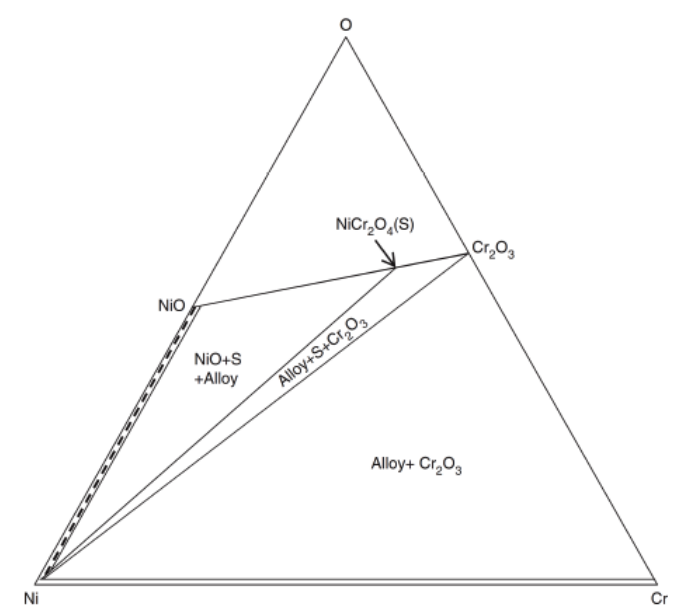

Figure 3 The same cross-section for the Ni-Cr-O system, according to the experimental data of Ref. [27]. Reprinted with permission of Springer Verlag, New York.

The comparison of these two diagrams demonstrates their remarkable similarity, although the computed one contains more details, e.g., on the structure of the metallic "alloy" phase.

Noble metals $(\mathrm{Pt}, \mathrm{Au})$ show a behavior similar to Ni (i.e., chromia formation at the surface is thermodynamically favorable and the evaporation of $\mathrm{Cr}$ species depends mainly on the interplay between the oxidation and diffusion kinetics). The 5 -valent transition metals $(\mathrm{V}, \mathrm{Nb}$, and $\mathrm{Ta}$ ) possess similar values of the oxide dissociation pressure compared to $\mathrm{Cr}$ (Figure 1). This implies that in the freshly applied coating, a coating metal oxide film forms at the surface immediately which may form an additional barrier for the $\mathrm{Cr}$ migration through it. This is true for nickel coatings as well.

. Another interesting example of a coating material for stainless steel interconnects could be silicon because: (i) it should stop the Cr migration inside the Si layer due to the formation of a stable compound $\mathrm{SiCr}_{2}$ and (ii) the $\mathrm{Si}$ oxide formation is energetically more favorable than $\mathrm{Cr}$ 


\section{Submitted for publication in International Journal of Hydrogen Energy}

oxides, Figure 1. Problems associated with this type of coatings were discussed extensively in [28-34]

\section{First-Principles Calculations}

To investigate the structural characteristics of $\mathrm{Cr}$ doped $\mathrm{Ni}$ coatings as well as initial stages of oxidation of the coating surface, we constructed a model system comprised of 4- and 6-layerthick (111) - oriented $\mathrm{Ni}$ slabs with different distribution of $\mathrm{Cr}$ impurities (considered as substitutional defects in the bulk and at the surface layer) and different local structures. We optimized all of the considered geometries using density-functional theory. The vacuum layer between periodically repeated slabs (in the direction perpendicular to the slab) was $>12 \AA$, which is enough to avoid direct interactions between neighboring supercells. The size of periodic supercells in the lateral direction (parallel to the slab), was also chosen large enough to avoid interaction of individual defects positioned in neighboring supercells. In most of the calculations we used supercells with $36(6 \times 6)$ and $64(8 \times 8)$ atoms in the surface layer.

Although the number of doped Ni slab supercells one could construct in such a way is very large, an important fact is that the formation energy of defect as well as its migration barrier is defined mainly by the local structure of the surrounding network, i.e., by 1-2 nearest neighboring layers. Therefore, we did not perform a full systematic study of the statistics for all the possible supercells with different topology. Instead, we formed different local structures of $\mathrm{Cr}$ doped $\mathrm{Ni}$ slab supercells in the bulk and at the surface by simple permutation of nearest neighboring cations with further structure relaxation.

The calculations were based on the generalized gradient approximation (GGA) for exchange and correlation, and plane waves [35]. We used the GGA of Perdew, Burke, and Ernzerhof (PBE) [36], which gives good results for chemisorption of molecules at transition-metal surfaces. Projected Augmented Wave (PAW) scalar relativistic pseudopotentials $[37,38]$ and the VASP code [39] were used. The energy cutoff for the plane-wave basis was set at $500 \mathrm{eV}$, and all 
integrations over the Brillouin zone were done using the Monkhorst-Pack scheme with eight $\mathbf{k}$ points in the relevant irreducible wedge [40]. Inclusion of additional $\mathbf{k}$ points was found to have minimal effect on the total-energy differences of interest here. The maximal total number of atoms in the periodic supercell was 384 . For each supercell, we relaxed all atoms until the quantum-mechanical force on each atom became smaller than $0.02 \mathrm{eV} / \AA$. All the calculations were spin-polarized. Activation barriers were calculated using the nudged-elastic-band method [41].

a)

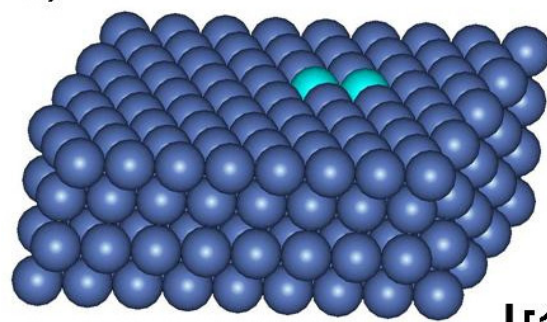

c)

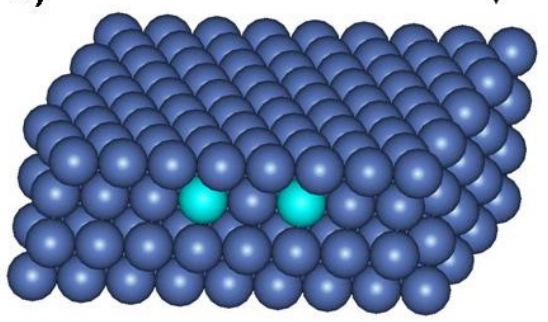

b)
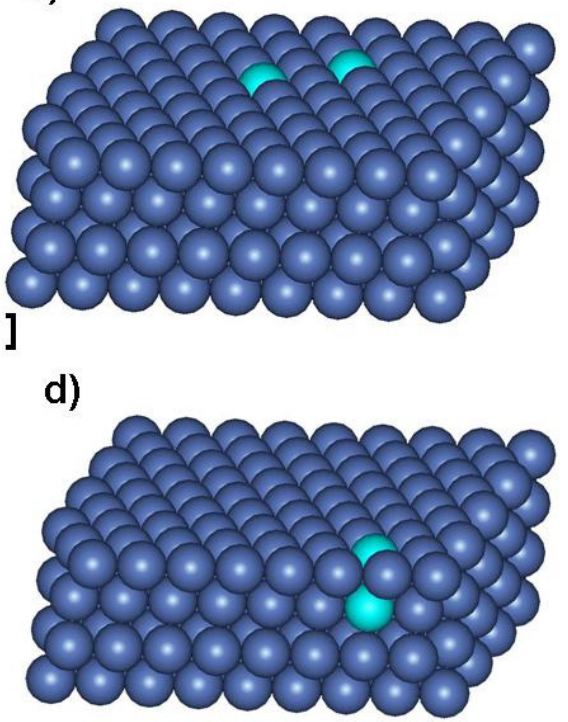

Figure $4 \mathrm{Ni}$ (111) slab with two substitutional $\mathrm{Cr}$ impurities which are: (a) nearest neighbors in the surface layer; (b) non-nearest neighbors in the surface layer; (c) non-nearest neighbors in the subsurface layer; (d) nearest neighbors with one impurity in the surface, another - in the subsurface layer. $\mathrm{Ni}$ atoms are shown in blue, $\mathrm{Cr}-$ in cyan.

Calculations indicate that any substitutions of $\mathrm{Ni}$ by $\mathrm{Cr}$ produce minimal structural distortion of the lattice which is related to the close atomic radii of the both types of atoms (Figure 4). The first important observation is that positioning a $\mathrm{Cr}$ atom at the surface layer is energetically unfavorable - moving an individual $\mathrm{Cr}$ atom from the surface to the first subsurface layer reduces 
the total energy of the system by $0.6 \mathrm{eV}$. At the same time, within one layer (both surface or subsurface) $\mathrm{Cr}$ atoms prefer to stay away from each other - the total energy of the system declines by $0.8 \mathrm{eV}$ for the cases when two $\mathrm{Cr}$ atoms within one layer are not nearest neighbors (Figures $4 b, 4 c$ ) in comparison with the case when they are nearest neighbors (Figure 4a). The most energetically unfavorable local structure corresponds to the case when two $\mathrm{Cr}$ atoms are nearest neighbors and one of them is positioned at the surface, and another - in the subsurface layer (Figure 4d). The energy of this structure is about $0.4 \mathrm{eV}$ higher than the energy of the structure with two neighboring surface chromium atoms shown in Figure 4a.

First, these results are consistent with a well known fact that the solubility of $\mathrm{Cr}$ in $\mathrm{Ni}$ matrix is very high. Second, in a pure metallic system (before the oxidation) chromium prefers to be homogeneously distributed in the Ni matrix rather than to form any $\mathrm{Cr}$ clusters. Third, chromium always has a tendency to leave the surface and to go into subsurface layers or even deeper into the bulk, i.e., one would expect that the surface consists of $\mathrm{Ni}$ atoms only which makes $\mathrm{Cr}$ species evaporation unlikely.

Oxidation of the coating starts with bonding of atomic oxygen to the coating surface. Investigation of all the details of the oxidation process is beyond the scope of this work. However, preliminary calculations indicate that for any possible position of adsorbed atomic oxygen at the $\mathrm{Cr}$ doped $\mathrm{Ni}$ (111) surface (a "top" position when $\mathrm{O}$ is attached to one metal atom at the surface, a "bridge" - $\mathrm{O}$ is attached to two metal atoms, and a "hollow" - $\mathrm{O}$ is attached to three atoms), the presence of $\mathrm{Cr}$ atoms at the surface makes the attachment of oxygen energetically favorable. For example, $\mathrm{O}$ bridge formed at the surface between two $\mathrm{Cr}$ atoms is 0.8 $\mathrm{eV}$ energetically favorable over the formation of a Ni-O-Ni bridge and $0.6 \mathrm{eV}$ over the formation of a Ni-O-Cr bridge. Therefore, the presence of oxygen has a tendency to increase the segregation of $\mathrm{Ni}$ and $\mathrm{Cr}$ atoms in the oxide phase (which is consistent with the Ellingham-Richardson diagram for the Cr-Ni system, see Figure 1), i.e., the real local chemical composition of the oxide 
phase is formed by the competition between the processes of solubility of $\mathrm{Cr}$ in oxidized $\mathrm{Ni}$ matrix and $\mathrm{Cr}$ clustering in $\mathrm{NiO}$.

\section{Diffusion Modeling}

Diffusion modeling for the SS441 / Ni diffusion couple was conducted using the commercial software package called DICTRA. In this abbreviation, DICTRA stands for "DIffusionControlled phase TRAnsformations" $[42,43]$. For the goals of the present study it is sufficient to say that the two sets of critically assessed parameters (see Figure 5) are necessary to solve the coupled problem of multi-component diffusion: mobilities of different components and the corresponding driving forces of diffusion (second partial derivative of the Gibbs free energy with respect to concentration of an " $i$ " factors". Data on mobility are obtained from diffusion experiments and first-principle atomistic calculations [44-46]. In our calculations we used the commercially available database for mobility of components in Ni-based superalloys, MOBFE1 [47]. The second derivatives of the Gibbs free energy are calculated for each time step using ThermoCalc. The procedure of stable numerical differentiation of data is employed (based on the preliminary smoothing of the data and proper sampling procedure) that allows resolving this problem successfully ${ }^{2}$. It is for this reason that the diffusion calculations take much more time than any single point, stepping and even mapping thermodynamic calculations.

The outcome is the solution of the underlying set of the coupled partial differential equations (always in 1D) that represents the concentration profiles of all alloy components across the interface between the two materials of interest. Typically, one considers fcc / fcc interfaces and

\footnotetext{
${ }^{2}$ In general, in the $L_{2}$ space of square-integrable functions the numerical differentiation of data represents an ill-posed problem in the sense of Hadamard [48]. This conclusion is based upon that fact the corresponding Voterra's integral equation of the $1^{\text {st }}$ kind is nothing but the Newton-Leibnitz formula that needs to be solved with respect to the $1^{\text {st }}$ derivative [49]. The second derivative is the results of application of this formula twice. When such a problem is solved using the right algorithms (e.g., regularization in the Sobolev space $W_{2}^{1}$, the uncertainty in the solution is of the same order of magnitude as that of the original experimental data
} 
materials for such computational diffusion studies. In many cases it is also possible to consider the fcc / bcc interfaces. However, sometimes the numerical complications (divergence, loss of solution stability) may become overwhelming, and in such situations it becomes necessary to use the so-called "homogenization" techniques $[50,51]$. This advanced approach was adopted in the present study.

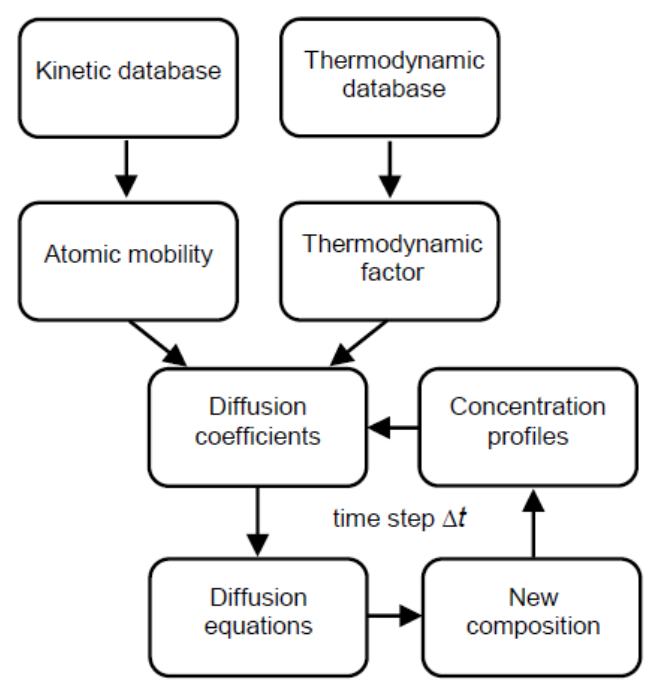

Figure 5 The general flowchart for diffusion calculations using DICTRA [43].

This modeling, however, is applicable only to very early stages of the diffusion processes, i.e., before the massive oxidation of the coating film occurs. In a real life, however, one cannot neglect oxidation processes at typical operating temperatures $\left(700^{\circ} \mathrm{C}-900^{\circ} \mathrm{C}\right)$ for solid oxide devices, especially in the presence of water vapor. Experiments show that in such conditions Ni coating film becomes completely oxidized quite soon. Therefore, Figure 6 could be used for description of the initial stages of the Cr migration only.

Figures $6 \mathrm{a}$ and $6 \mathrm{~b}$ show the $\mathrm{Cr}$ concentration profiles for the diffusion process between the $\mathrm{Ni}$ coating film and Ferrite 441 stainless steel substrate calculated by the DICTRA v.25 software [35]. While Figure 6a corresponds to the initial modeled concentration profile (simulation time $t$ $=0 \mathrm{~s}), 6 \mathrm{~b}$ provides the results for the last "moment" of our simulation, at 19,906s. It took about 2 
weeks of continuous computer simulation to get to this point, so a decision was made to terminate the modeling process.

At the initial moment $(t=0 \mathrm{~s})$, a clean Ni coating film of a thickness of $5 \mu \mathrm{m}$ is positioned on top of the 441 steel substrate modeled with a slab of $20 \mu \mathrm{m}$ thick. Both the coating and substrate are supposed to be unoxidized. We arrived at the initial configuration with very significant supersaturation of $\mathrm{Cr}$ in the bcc-phase (441 steel) based upon the results of the preliminary thermodynamic simulations. These simulations (conducted using the Thermo-Calc v.S software) allowed us to estimate the $\mathrm{Cr}$ equilibrium concentration at the bcc-phase / fcc-Ni interface on the 441 ferritic steel. The results were as follows: while in the bulk of that material (i.e., some $3 \mu \mathrm{m}$ from the interface), the $\mathrm{Cr}$ weight fraction was equal to the equilibrium value of $\mathrm{x}_{\mathrm{Cr}, \mathrm{bcc}} \sim 0.176$, at the interface its concentration was as high as $\mathrm{x}_{\mathrm{Cr}, \mathrm{bcc}} \sim 0.256$. It is this supersaturation effect at the fcc-Ni / bcc-441 steel that makes computer modeling of the diffusion process so difficult.

From these results one can notice that the $\mathrm{Cr}$ supersaturation at the $441 / \mathrm{Ni}$ interface persists even at $t=19,906 \mathrm{~s}$. In a sense, the chromium gets "stopped" at the interface, thereby considerably delaying its penetration into the Ni coating. At $\mathrm{t}=3600 \mathrm{~s}, 5400 \mathrm{~s}$, and $7200 \mathrm{~s}$ the $\mathrm{Cr}$ the depth of the Cr penetration into Ni remains practically unchanged and equal to that at $3600 \mathrm{~s}$.

(a)

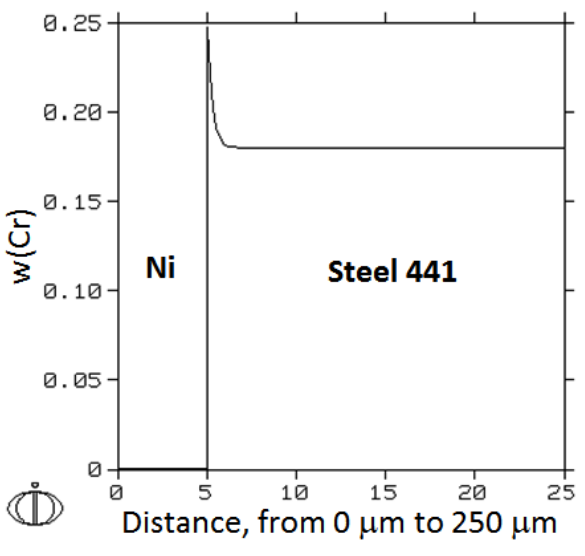

(b)

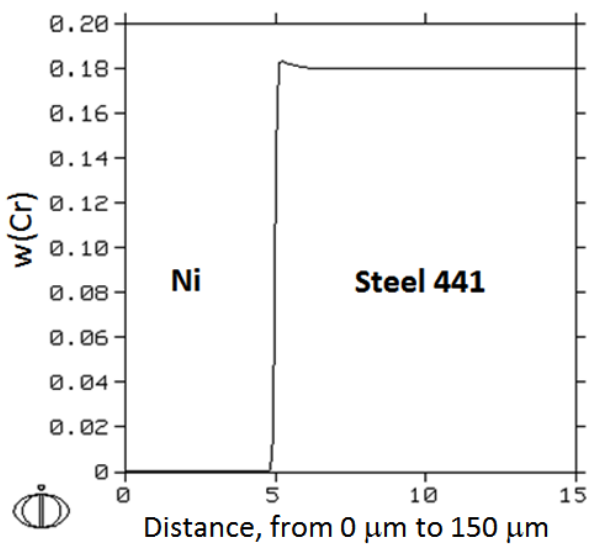


Figure 6 (a) Initial concentration profile of $\mathrm{Cr}$ across the interface; and (b) The final concentration profile at $\sim 19,906 \mathrm{~s}$

Finally, at $t=19,906 \mathrm{~s}$ (the last moment of simulation) this picture does not change qualitatively. Consequently, one could speculate that the formation of this initial $\mathrm{Cr}$ supersaturation prevents the diffusion of $\mathrm{Cr}$ into Ni quite effectively. We could not say anything about the nature of the diffusion process beyond this last moment of time. However, the general picture of the mechanisms arresting the diffusion of chromium into the nickel coating seems to be reasonably well established.

Thermodynamics analysis conducted above indicated that the three oxide phases that can form on $\mathrm{Ni}-\mathrm{Cr}$ alloys are $\mathrm{NiO}, \mathrm{Cr}_{2} \mathrm{O}_{3}$, and the spinel $\mathrm{NiCr}_{2} \mathrm{O}_{4}$, see Figure 2 above.

Unfortunately, diffusion databases for multi-component oxide materials are absent, so we couldn't apply the DICTRA codes directly to address this problem. Consequently, we here discuss it qualitatively based on the existing experimental materials on oxidation of these materials.

The only oxide formed during nickel oxidation is the $\mathrm{NiO}$, which has the rock salt cubic crystal structure and is metal deficient, with the predominant defects being $\mathrm{Ni}$-cation vacancies. The rate of oxidation of nickel is controlled by the outward diffusion of nickel cations by a vacancy mechanism through the $\mathrm{NiO}$ barrier layer. The value of the Ni diffusion coefficient in the $\mathrm{NiO}$ lattice at $\mathrm{T}=800{ }^{\circ} \mathrm{C}$ is quite low $\mathrm{D} \sim 10^{-14} \mathrm{~cm}^{2} \mathrm{~s}^{-1}[52]$. However, it is well known that the rate of oxidation of nickel is controlled by cation grain - boundary diffusion of $\mathrm{Ni}$ in NiO. The grain boundary diffusion coefficient for $\mathrm{Ni}$ cations at $\mathrm{T}=800^{\circ} \mathrm{C}\left(\mathrm{D} \sim 10^{-8.5} \mathrm{~cm}^{2} \mathrm{~s}^{-1}\right.$; the Ni diffusion through dislocations also is much faster than the lattice diffusion but slower than the cation grain-boundary diffusion) is much higher than the lattice diffusion coefficient, and very simple estimate shows that $10 \mu \mathrm{m}$ thick Ni coating film will be completely oxidized within $10^{2}-$ $10^{3}$ seconds. Therefore, $\mathrm{Cr}$ from the 441 ferritic steel most likely will diffuse through NiO rather 


\section{Submitted for publication in International Journal of Hydrogen Energy}

than through unoxidized Ni metal, and one could expect that at any point within the coating layer we have an oxidized $\mathrm{Ni}-\mathrm{Cr}$ alloy with some $\mathrm{Cr}$ concentration specific for this point (which may evolve in time).

It was shown that the microstructure of oxidized $\mathrm{Ni}-\mathrm{Cr}$ alloy is different for different $\mathrm{Cr}$ concentrations [52]. At very low concentrations, $\mathrm{Cr}$ oxide forms a solid solution in a $\mathrm{NiO}$ matrix. When the solubility limit is exceeded, $\mathrm{Cr}_{2} \mathrm{O}_{3}$ reacts with $\mathrm{NiO}$ and is precipitated out as $\mathrm{NiCr}_{2} \mathrm{O}_{4}$ spinel. Alloys containing approximately $10-20 \mathrm{wt} . \% \mathrm{Cr}$ begin to form protective $\mathrm{Cr}_{2} \mathrm{O}_{3}$ layers individual $\mathrm{Cr}_{2} \mathrm{O}_{3}$ grain have a tendency to coagulate and form structures with larger characteristic length scales. Concentrated Ni-Cr alloys containing more than about $20 \mathrm{wt} \% \mathrm{Cr}$ form continuous $\mathrm{Cr}_{2} \mathrm{O}_{3}$ layers which oxidize relatively slowly and protect the substrate from further oxidation because these layers allow only "slow" Cr lattice diffusion (D $\left.\sim 10^{-14} \mathrm{~cm}^{2} \mathrm{~s}^{-1}\right)$ and exclude faster short-circuit diffusion through grain-boundaries.

Now we can qualitatively discuss the mechanism of reducing $\mathrm{Cr}$ oxidation by $\mathrm{Ni}$ coating. When pure unoxidized $\mathrm{Ni}$ coating film is deposited at the stainless steel substrate and the interconnect is put into a solid state device at operational regime $-\mathrm{T} \sim 800{ }^{\circ} \mathrm{C}$, oxygen and water vapor environment, the coating film oxidizes very fast, and in order to get the free coating surface (where $\mathrm{Cr}$ species could start to evaporate) depends on $\mathrm{Cr}$ migration through $\mathrm{NiO}$ film. Although we do not know all of the details of transport of $\mathrm{Cr}$ through $\mathrm{NiO}$ and $\mathrm{Ni}$ through $\mathrm{Cr}_{2} \mathrm{O}_{3}$, the diffusion of both $\mathrm{Ni}$ and $\mathrm{Cr}$ atoms through the $\mathrm{NiCr}_{2} \mathrm{O}_{4}$ spinel is slow and its rate is comparable to the lattice diffusion of $\mathrm{Cr}$ in $\mathrm{Cr}_{2} \mathrm{O}_{3}$ and $\mathrm{Ni}$ in $\mathrm{NiO}\left(\mathrm{D} \sim 10^{-14} \mathrm{~cm}^{2} \mathrm{~s}^{-1}\right)$.

Therefore, the formation of $\mathrm{NiO}$ prevents $\mathrm{Cr}$ penetration through the coating. At the same time, the electrical conductivity of $\mathrm{NiO}$ is several orders of magnitude higher that the conductivity of chromia, i.e., the nickel oxide layer does not disturb normal functioning of interconnect. The $\mathrm{Ni}$ vaporization rate from $\mathrm{NiO}$ is more than 2 orders of magnitude lower than the $\mathrm{Cr}$ vaporization from Crofer 22 APU stainless steel and can most probably be neglected. However, it would be interesting to check whether the external part of the initial layer of $\mathrm{Ni}$ 


\section{Submitted for publication in International Journal of Hydrogen Energy}

remains a single phase oxide or whether it transforms into a $\mathrm{Cr}$-containing spinel phase, which then might lead to an enhanced $\mathrm{Cr}$ vaporization. Simple calculations conducted using the $\mathrm{Cr}$ diffusion coefficient in the $\mathrm{NiCr}_{2} \mathrm{O}_{4}$ spinel give an estimate that for the $\mathrm{Ni}$ film of $10 \mu \mathrm{m}, \mathrm{Cr}$ will reach the free coating surface in $\sim 10^{4}$ hours. This result looks quite reasonable and makes the Ni foils or coatings suitable for possible commercial applications in solid oxide devices.

The results of first-principles calculations as well as thermodynamic and diffusion modeling discussed in this paper are in a very good agreement with recent experimental measurements for $\sim 100 \mu \mathrm{m}$ Ni coating on top of the SUS430 alloy [53]. In Ref. [53] it was proven that: (i) the presence of Ni coating layer reduces the rate oxidation of the SUS430 alloy by the factor of about fifty (coating slows down oxygen diffusion inside the interconnect also); (ii) after a significant time spent in operational regime, oxidized $\mathrm{NiO}$ coating layer shows very regular structure without a significant number of structural defects, cracks, and spallation; (iii) chromium species formed in oxidative environment practically stop to diffuse through the coating layer. All of these conclusions based on experimental measurements are completely consistent with assumptions and models employed in calculations described above.

\section{Conclusions}

We used a combination of first-principles calculations, thermodynamics, and diffusion modeling for $\mathrm{Cr}$ behavior in a Ni coating positioned on the top of 441 ferritic stainless steel. We found that the Cr migration through the coating film is defined by the two competing factors: (i) high $\mathrm{Cr}$ solubility in unoxidized Ni matrix, and (ii) possible chromium and nickel oxides segregation in oxidized Cr-Ni alloys. Additionally, the diffusion of $\mathrm{Cr}$ into $\mathrm{Ni}$ is impeded due to the formation of the Cr supersaturated zone, at least in the initial period of diffusion (up to 5.5 hours). Also, the coating oxidation process significantly increases the resistance of the film to $\mathrm{Cr}$ migration and is crucially important for the minimization of $\mathrm{Cr}$ species evaporation from $\mathrm{Cr}$ containing interconnects. These results and corresponding analysis will eventually provide 
practical recommendations on modifying the solid oxide devices multicomponent systems to minimize $\mathrm{Cr}$ transport and other undesirable processes, thus increasing the lifetime of SOEC and SOFC devices and making it possible to widen their use in industrial and/or commercial applications.

Acknowledgments and Disclaimer The authors would like to express gratitude to the Next Generation Nuclear Plant (NGNP) Program Management (Mr. Michael W. Patterson, Mr. Charles V. Park) at INL for their continuous support of this research effort. This research was also supported in part by a grant of computer time from High Performance Computer (HPC) Center at the INL. Thanks to Dr. James E. O’Brien for productive discussions. This manuscript has been authored by Battelle Energy Alliance, LLC under Contract No. DE-AC07-05ID14517 with the U.S. Department of Energy.

The United States Government retains and the publisher, by accepting the article for publication, acknowledges that the United States Government retains a nonexclusive, paid-up, irrevocable, world-wide license to publish or reproduce the published form of this manuscript, or allow others to do so, for United States Government purposes.

\section{References}

[1] F. Tietz, Mater. Sci. Forum 426-432 (2003) 4465-4470.

[2] J.S. Herring, J.E. O’Brien, C.M. Stoots, G.L. Hawkes, J.J. Hartvigsen, M. Shahnam, Progress in high-temperature electrolysis for hydrogen production using planar SOFC technology, Int. J. Hydrogen Energy 32 (2007) 440-50.

[3] X. Li, Fuel cells. In: K. Frank, Y.D.Goswami, editors. Handbook of energy efficiency and renewable energy, Boca Raton, FL: CRC Press/Taylor\&Francis Group; 2007 [Chapter 28]. 
[4] W.J. Quadakkers, J. Piron-Abellan, V. Shemet, L. Singheiser, Mater. High Temp. 20 (2003) 115-127.

[5] S. Taniguchi, M. Kadowaki, H. Kawamura, T. Yasuo, Y. Akiyama, Y. Miyake, T. Saitoh, J. Power Sources 55 (1995) 73-79.

[6] S.P. Simner, M.D. Anderson, G.-G. Xia, Z. Yang, L.R. Pederson, J.W.Stevenson, J. Electrochem. Soc., 152 (2005) A740-A745.

[7] S.C. Paulson, V.I. Birss, J. Electrochem. Soc. 151 (2004) A1961-A1968.

[8] S.P. Jiang, J.P. Zhang, L. Apateanu, K. Foger, J. Electrochem. Soc. 147 (2000) 40134022.

[9] S.P. Jiang, S. Zhang, Y.D. Zhen, J. Mater. Res. 20 (2005) 747-758.

[10] K. Hilpert, D. Das, M. Miller, D.H. Peck, R. Weiß, J. Electrochem. Soc. 143 (1996) $3642-3647$.

[11] C.J. Fu, K.N. Sun, X.B. Chen, N.Q. Zhang, D.R. Zhou, Electrochimica Acta 54 (2009) 7305-7312.

[12] C. Johnson, N. Orlovskaya, A. Coratolo, C. Cross, J. Wu, R. Gemmen, X. Liu, Int. J. Hydr. Energy 34 (2009) 2408-2415.

[13] X. Chen, B. Hua, J. Pu, J. Li, L. Zhang, S. P. Jiang, Int. J. Hydr. Energy 34 (2009) $5737-5748$.

[14] Y. Matsuzaki, I. Yasuda, J. Electrochem. Soc. 148 (2001) A126-A131.

[15] E. Konysheva, H. Penkalla, E. Wessel, J. Mertens, U. Seeling, L. Singheiser, K. Hilpert, J. Electrochem. Soc. 153 (2006) A765-A773.

[16] B. J. Ingram, T. A. Cruse, and M. Krumpelt, J. Electrochem. Soc. 154 (2007) B1200-B1205. 
[17] X. Chen, L. Zhang, S. P. Jiang, J. Electrochem. Soc. 155 (2008) B1093-B1101.

[18] H. Yokokawa, T. Horita, N. Sakai, K. Yamaji, M.E. Brito, Y.-P. Xiong, H. Kishimoto, Solid State Ionics 177 (2006) 3193-3198.

[19] M. Stanislowski, J. Froitzheim, L. Niewolak, W.J. Quadakkers, K. Hilpert, T. Markus, L. Singheiser, Journal of Power Sources 164 (2007) 578-589.

[20] G. V. Samsonov, The Oxide Handbook, IFI/Plenum Data Company, New York, 1982.

[21] ThermoCalc Classic Version S User's Guide, P. Shi and B. Sundman Editors, ThermoCalc Software AB, Stockholm, Sweden (2010).

[22] H.L. Lukas, S.G. Fries, and Bo Sundman, Computational Thermodynamics (The CALPHAD Method), Cambridge University Press, Cambridge (2007)

[23] M. Hillert, Phase Equilibria, Phase Diagrams, and Phase Transformations, Cambridge University Press, Cambridge, UK (2007)

[24] Zi-Kui Liu, First-Principles calculations and CALPHAD Modeling of Thermodynamics, Journal of Phase equilibria and Diffusion, published online 03 September (2009)

[25] N. Birks, G.H. Meier, and F.S. Pettit, Introduction into the high temperature oxidation of metals, Cambridge University Press, Cambridge (2006).

[26] A. Chirkin, Oxidation-Induced Phase Transformations and Lifetime Limits of Chromia-Forming Nickel-Base Alloy 625, M.S. Thesis, RWTH, Aachen (December, 2011) 
[27] A.D. Dalvi and D.E. Coates: Review of diffusion path concept and its application to high-temperature oxidation of binary-alloys, Oxidation of Metals, 5 (1972) 113.

[28] A. Hauch, S.H. Jensen, J. Bilde-Sørensen, M.B.Mogensen, JECS, 154 (2007)

A619-A626

[29] A. Hauch, S.H. Jensen, S. Ramousse, M.B. Mogensen, , JECS, 153, (2006), A1741-A1747.

[30] S.H. Jensen, P.H. Larsen, M. Mogensen, Int. J. Hydrogen Energy 32 (2007) $3253-3258$

[31] S.H. Jensen, A. Hauch, P.V. Hendriksen, M. Mogensen, N. Bonanos and T. Jacobsen, JECS, 154(12) (2007) B1325-B1330

[32] A. Hauch, J.R. Bowen, L.T. Kuhn and M. Mogensen, Electrochem. \& Solid State Letts., 11(3) (2008) B38-B41

[33] S.N. Rashkeev and M.V. Glazoff, Applied Physics Letters, 99 (24 October 2011) article 173506

[34] S.N. Rashkeev and M.V. Glazoff, International Journal of Hydrogen Energy, vol.37 (2012) 1280-1291

[35] M.C. Payne, M.P. Teter, D.C. Allan, T.A. Arias, J.D. Joannopoulos, Rev. Mod. Phys. 64 (1992) 1045-1097.

[36] J.P. Perdew, K. Burke, M. Ernzerhof, Phys. Rev. Lett. 77 (1996) 3865-3868.

[37] P.E. Blöchl, Phys. Rev. B 50 (1994) 17953-17979.

[38] G. Kresse, J. Joubert, Phys. Rev. B 59 (1999) 1758-1775. 
[39] G. Kresse, J. Hafner, Phys. Rev. B 48 (1993) 13115-13118; also see G.Kresse, J. Furthmüller, Phys. Rev. B, 54 (1996) 11169-11186.

[40] D.J. Chadi, M.L. Cohen, Phys. Rev. B, 8 (1973) 5747-5753.

[41] H. Jonsson, G. Mills, K.W. Jacobsen, Classical and Quantum Dynamics in Condensed Phase Systems; World Scientific, Singapore, 1998, p 385

[42] DICTRA Version 25 User's Guide, 2010, Thermo-Calc Software AB, Stockholm, Sweden.

[43] A. Borgenstam, A. Engstrom, L. Hoglund, and J. Agren, DICTRA, a tool for simulation of diffusional transformations in alloys, J. of Phase Equilibria, 21(2000) 269

[44] M. H. Evans, X.-G. Zhang, J.D. Joannopoulos, and S. T. Pantelides, FirstPrinciples Mobility Calculations and Atomic-Scale Interface Roughness in Nanoscale Structures, Phys. Rev. Letts., 95 (2005) 106802

[45] J. Agren, Numerical Treatment of Diffusional Reactions in Multicomponent Alloys, J. Phys. Chem. Solids, 43 (1982) 385-391

[46] J.O. Andersson and J. Agren, Models for Numerical Treatment of Multicomponent Diffusion in Simple Phases, J. Appl. Phys., 72 (1992) 1350-1355

[47] J. O. Andersson, T. Helande, L. Hoglund, P. Shi, B. Sundman, CALPHAD: Computer Coupling of Phase Diagrams and Thermochemistry, 26 (2002) 273-312.

[48] J. Hadamard, Sur les problèmes aux dérivées partielles et leur signification physique Paris, Gauthier-Villars, pp. 49-52 (1902).

[49] A.N. Tikhonov, and V.Y. Arsenin, Solutions of Ill-Posed Problems, New York, Winston Publishers (1977). 
[50] H. Larsson, A. Engström, A homogenization approach to diffusion simulations applied to $(\alpha+\gamma)$ Fe-Cr-Ni diffusion couples, Acta Materialia, 54 (2006) 24

[51] H. Larsson, L. Höglund, Multiphase diffusion simulations in 1D using the DICTRA homogenization model, CALPHAD: Computer Coupling of Phase Diagrams and Thermochemistry 33 (2009) 495-501

[52] D. F. Shriver and P. W. Atkins, Inorganic Chemistry. Oxford, U.K., Oxford University Press, 1999

[53] C.J. Fu, K.N. Sun, X.B. Chen, N.Q. Zhang, D.R. Zhou, Corrosion Science 50 (2008) 1926-1931 
a)

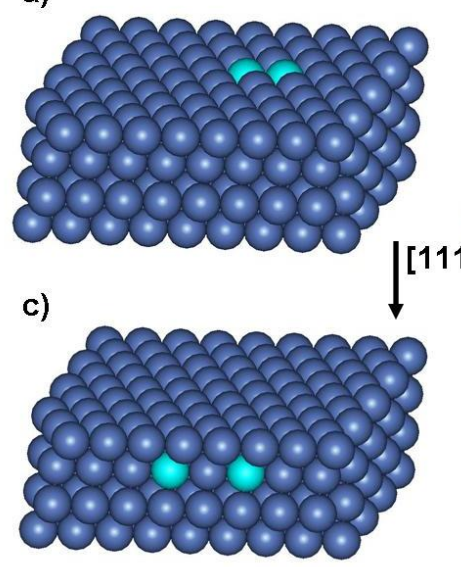

b)

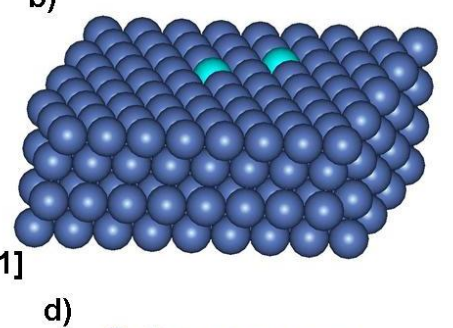

d)

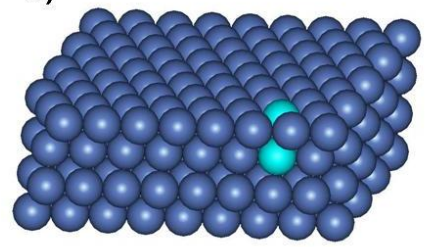

Ni (111) slab with two substitutional Cr impurities which are: (a) nearest neighbors in the surface layer; (b) nonnearest neighbors in the surface layer; (c) non-nearest neighbors in the subsurface layer; (d) nearest neighbors with one impurity in the surface, another - in the subsurface layer. $\mathrm{Ni}$ atoms are shown in blue, $\mathrm{Cr}$ - in cyan.

Our calculations indicate that any substitutions of $\mathrm{Ni}$ by $\mathrm{Cr}$ produce minimal structural distortion of the lattice which is related to the close atomic radii of the both types of atoms. The first important observation is that positioning a $\mathrm{Cr}$ atom at the surface layer is energetically unfavorable - moving an individual $\mathrm{Cr}$ atom from the surface to the first subsurface layer reduces the total energy of the system by $0.6 \mathrm{eV}$. At the same time, within one layer (both surface or subsurface) $\mathrm{Cr}$ atoms prefer to stay away from each other - the total energy of the system declines by $0.8 \mathrm{eV}$ for the cases when two $\mathrm{Cr}$ atoms within one layer are not nearest neighbors (Figures b, c) in comparison with the case when they are nearest neighbors (Figure a). The most energetically unfavorable local structure corresponds to the case when two $\mathrm{Cr}$ atoms are nearest neighbors and one of them is positioned at the surface, and another - in the subsurface layer (Figure d). The energy of this structure is about $0.4 \mathrm{eV}$ higher than the energy of the structure with two neighboring surface chromium atoms shown in Figure a. These results are consistent with the fact that the solubility of $\mathrm{Cr}$ in $\mathrm{Ni}$ matrix is very high. Also, in a pure metallic system (before the oxidation) chromium prefers to be homogeneously distributed in the Ni matrix rather than to form any Cr clusters. Finally, chromium always has a tendency to leave the surface and to go into subsurface layers, i.e., one would expect that the surface consists of $\mathrm{Ni}$ atoms only. This makes $\mathrm{Cr}$ species evaporation unlikely. 